\title{
O ENSINO DE REABILITAÇÃO: EXPECTATIVAS DE ESTUDANTES DE ENFERMAGEM
}

\author{
Ana Cristina Mancussi e Faro*
}

\begin{abstract}
FARO, A.C.M. e O ensino de reabilitação: expectativas de estudantes de enfermagem. Rev.Esc.Enf.USP, v.30, n.2, p. 332-9, ago. 1996.

Este trabalho mostra as expectativas de estudantes de enfermagem quanto ao ensino de reabilitação durante o curso de graduação em enfermagem. Alunos do oitavo semestre e do segundo semestre do curso de Graduação em Enfermagem responderam um questionário específico para cada grupo e apontaram suas expectativas caracterizando uma proposta para o ensino de reabilitação em enfermagem.
\end{abstract}

UNITERMOS: Reabilitação. Ensino.

\section{INTRODUÇÃo}

A ampliação das atividades do enfermeiro no campo da saúde, assim como em outros campos, revela não $\mathbf{6} 6$ a sua capacidade de adequação, mas também a parcela de responsabilidade que é inerente á formação desse profissional. Dentre o processo evolutivo desta profissão, trataremos do assunto reabilitação.

O trabalho de reabilitação global da pessoa portadora de limitação física, no Brasil começou a ganhar espaço, principalmente, a partir de XXIX Congresso Brasileiro de Enfermagem que aconteceu por volta de 1980. 'Tal fato, deve-se à vivência destes profissionais nos cuidados aos pacientes que por razões diversas razões apresentavam seqüelas prejudicando a sua funcionalidade, tornando a reabilitação oportuna para amenizar os pontos negativos e valorizar os pontos positivos, resultantes de tais seqüelas, que o indivíduo apresenta (COMARÚ, 1980).

O ensino de reabilitação, no curso de enfermagem deveria ser instituído formalmente uma vez que é importante ter-se o conhecimento dos cuidados preventivos, curativos e reabilitatórios visto que a enfermagem atua nestes três

* Enfermeira. Professor Doutor do Departamento de Enfermagem Médico-Cirúrgica da Escola de Enfermagem da USP. 
campos, e também por possibilitar aos alunos o conhecimento de conceitos e/ ou práticas de atuação nesta área, buscando assim, mostrar ao aluno a importância da reabilitação.

O cuidado primário à saúde (Primary health care - $\mathrm{PHC}$ ), como definido na Declaração de Alma-Ata, inclui cuidados preventivos, curativos e de reabilitação. A reabilitação faz parte do processo de prevenção terciária e tem como objetivo evitar as incapacidades, promovendo habilidades e a inserção social. (Organização Panamericana de Saúde - OPS/ OMS).

Segundo a análise da OPS/ OMS, o cuidado de Reabilitação, em geral é uma pequena parcela nos currículos de enfermagem, tanto na abordagem tebrica quanto no ensino de campo clínico. Ainda, esta organização internacional, considera relevante a estruturação formal de ensino de reabilitação nos currículos de enfermagem esclarecendo que o número de horas para este ensino varia de acordo com a grade curricular de cada curso de enfermagem e, que a proposta é de enfocar a prevenção terciária, particularmente a detecção de incapacidades, educando e motivando as comunidades para promover a integração social da pessoa com incapacidade.

Buscando, estruturar, o ensino de reabilitação no curso de graduação em enfermagem, fez-se oportuno o desenvolvimento deste trabalho, tendo como objetivo conhecer as expectativas dos alunos de enfermagem quanto ao ensino de reabilitação no curso de graduação em enfermagem.

\section{DEFINIÇÃO DE TERMOS E ESTRATÉGIAS (Organização Panamericana de Saúde)}

A definição de termos faz-se necessária para que haja compreensão das concepções propostas, bem como pela relação que há entre elas.

Organização Mundial da Saúde (OMS) em 1980, desenvolveu a classificação Internacional de Deficiências, Incapacidades e Desvantagem social, sendo que esta classificação tem sido traduzida e amplamente utilizada nos mais diversos países. Os termos são definidos como segue:

- Deficiência (Impairment): é representada por qualquer perda ou alteração de uma estrutura ou função psicológica, fisiológica ou anatômica.

- Incapacidade (disbility): qualquer restrição ou perda resultante de uma deficiência da capacidade de realizar uma atividade, dentro dos moldes e limites considerados normais para uma pessoa.

- Desvantagem (Handcap): é a condição social de prejuízo sofrida por um indivíduo, decorrente de uma deficiência ou incapacidade, que o limita ou mesmo o impede de desempenhar uma atividade considerada normal para a sua idade, sexo e fatores sócio-culturais. 
Quanto às estratégias, a OMS preconiza a prevenção de incapacidades, sendo que a prevencão primária compreende as medidas necessárias para prevenir doenças (congênitas ou não) ou traumas os quais poderiam resultar em incapacidades. A prevenção secundária enfatiza os tratamentos para as doenças e a prevencão terciária inclui todas as medidas voltadas para a redução ou eliminação das deficiências, incapacidades e desvantagem social. As medidas usadas para assistir deficientes são voltadas para a promoção de suas habilidades e atividades como o autocuidado, comunicação, locomoção de acordo com as normas sociais, ou, ainda, desenvolvendo habilidade vocacional profissionalização. (OMS, 1995).

\section{METODOLOGIA}

\section{População}

Este estudo foi realizado com estudantes de enfermagem de uma escola pública, no município de São Paulo. No momento da coleta de dados, haviam 61 alunos matriculados e cursando o oitavo semestre do curso de graduação em enfermagem. Também, matriculados e cursando o segundo semestre no mesmo curso de graduação, haviam outros 79 , sendo que estes cursam enfermagem na nova proposta curricular que vem sendo desenvolvida nesta escola.

\section{Coleta de dados}

No início do mês de agosto (1995), quando os alunos reiniciavam o ano letivo, e com a maioria das aulas com caráter teórico, a autora foi à sala de aulas quando estes alunos estavam reunidos e expôs, brevemente, sobre a pesquisa que estaria desenvolvendo, esclarecendo-lhes os objetivos. Então, entregou o questionário aos alunos, sendo que, cada um deles era acompanhado de uma carta a qual relatava sobre a importância da opinião de cada aluno sobre o ensino de reabilitação, bem como da não obrigatoriedade em responder o questionário, mas ressaltando o interesse e a motivação destes alunos. Ainda, garantia-lhes o anonimato e solicitava a devolução do questionário em três dias.

\section{Instrumentos}

Foram elaborados dois questionários com questões abertas, sendo cada um deles específico para os alunos do oitavo semestre (anexo I) da grade curricular antiga e para os do segundo semestre (anexo II), grade curricular iniciada, nesta escola, em 1994. Os dados referentes à caracterização destes alunos, em ambos os semestres se referiram à idade e sexo. As demais questões eram pertinentes 
ao transcorrer do curso de graduação para os alunos do oitavo e segundo semestres e, relacionavam-se à questão do ensino de Reabilitação no curso de enfermagem sob a btica do estudante

Os resultados foram apresentados de forma descritiva.

\section{RESULTADO E COMENTÁRIOS}

Foram entregues 61 questionários aos alunos cursando o oitavo semestre do curso de graduação em enfermagem, matriculados na disciplina Administração aplicada á enfermagem e, no período solicitado para devolução, constatamos o retorno de $5(8,2 \%)$ questionários, totalmente preenchidos. Assim os resultados que descrevemos a seguir são referentes às opiniões de alunos do oitavo semestre que procederam ao preenchimento e devolução dos questionários.

A totalidade dos respondentes pertence ao sexo feminino, com idades variando entre 21 e 27 anos. Apenas uma aluna exerce atividade remunerada, do tipo monitor-bolsista, na própria instituição de ensino.

Inicialmente perguntamos aos alunos se, durante o curso de graduação em enfermagem e até o momento desta pesquisa, houve disciplina(s) que abordassem o tema reabilitação ou deficiências e qual foi o conteúdo. Verificamos que três alunos responderam afirmativamente citando as disciplinas de Enfermagem Pediátrica abordando conceitos de deficiências, limitações e preconceitos; Enfermagem Psiquiátrica tratando a deficiência mental, inserção na sociedade e família, reabilitação de drogados e alcoolistas; Enfermagem Obstétrica e Ginecologica enfocando reabilitação psíquica e social de mulheres mastectomizadas; Enfermagem Médico-Cirúrgica, sem descrever o conteúdo abordado. Outros dois alunos não especificaram qualquer disciplina que tivessem esta temática.

Também, indagamos sobre a participação do aluno em atividade extracurricular (cursos, palestras, projetos, estágios, outros eventos) relativa à reabilitação ou deficiências e obtivemos resposta afirmativa de um aluno em curso de Primeiros Socorros, Reabilitação de menores drogados e Emergência Pediátrica. Os outros quatro alunos não tiveram participação em atividade extracurricular que abordasse tal temática.

Quando solicitamos a elaboração de um conceito para Reabilitação à partir dos seus conhecimentos, constatamos o enfoque do homem na situação de paciente/ cliente como agente participante na busca de um potencial remanescente em si próprio, objetivando sua reinserção na sociedade e família. Consideramos oportuno citar os cinco conceitos elaborados pelos alunos do oitavo semestre: 
Aluno 1: ... "pessoa que sofreu injúria levando a restrição de movimentos $e$ atividades normais de seus órgãos e/ou membros, adaptando-se da melhora forma possível, utilizando seu potencial e auxílio da equipe".

Aluno 2: ... “conhecimentos necessários à formação básica”.

Aluno 3: ..."processo através do qual o individuo procura desenvolver suas capacidades potenciais. ajudando-o a se integrar com maior satisfação e qualidade na sociedade e buscando sua auto-satisfação".

Aluno 4: ..."mostrar ao paciente que ele pode ser independente e produtivo na sua sociedade. Ajudá-lo a superar seus problemas e restrições. Porém, esse sentimento de independência deve estar dentro da pessoa".

Aluno 5: ... 'buscar com a pessoa que perdeu sua habilidade, formas de adaptação à sua realidade com a ajuda do enfermeiro, fisioterapeuta, médico e psicólogo".

A opinião dos alunos quanto aos aspectos que consideram de relevância para serem tratados durante o curso de graduação, refere-se tanto ao ensino teórico como prático (estágios ou ensino no campo) de reabilitação, citado por três alunos. Outros dois alunos não citaram como seria este ensino, mas todos (5) referiram o semestre em que acreditam viável uma disciplina e assim, verificamos que dois alunos optaram pelo quarto semestre, um aluno pelo segundo semestre, um aluno pelo sexto semestre, e um pelo ensino de conceitos e discussão no segundo semestre e, no quinto semestre a reabilitação de deficientes físicos, mentais e psiquiátricos, não caracterizando o que seria "mental" ou "psiquiatrico".

Ainda nestes aspectos, os alunos foram indagados quanto a necessidade ou não de uma disciplina específica, as respostas mostraram que dois alunos acreditam na estruturação de uma disciplina voltada para esta temática, outros dois alunos responderam negativamente à necessidade de uma disciplina única e uma não referiu. Também, houve sugestão de três alunos que este tema fosse abordado junto á disciplina de Enfermagem Médico-Cirúrgica.

Completando a apresentação dos resultados, passaremos a seguir aos dados obtidos à partir das respostas dos alunos do segundo semestre, os quais estão inseridos numa nova proposta curricular em implementação na instituição onde se realizou a pesquisa, desde 1994.

Foram entregues 79 questionários aos alunos cursando o segundo semestre do curso de graduação em enfermagem, matriculados na disciplina de Fundamentação do Processo de Cuidar e no período solicitado para a devolução, retornaram $16(20,3 \%)$, na sua maioria totalmente preenchidos. Deste total, seis alunos com mais de vinte anos de idade, quatro com 19 anos, dois com 21 anos, e um aluno para cada uma das idades: 18 anos, 22 anos, 27 anos e 32 anos. Quanto à questão gênero, quinze alunos são de sexo feminino e apenas um do sexo masculino. 
Como se tratava de alunos que estavam iniciando um curso de graduação, consideramos oportuno conhecer a experiência destes, ou seja, se já cursaram ou não outras faculdades. Assim, verificamos que a maioria deles (14) estava fazendo um curso de graduação pela primeira vez, sendo que outros dois alunos tinham os cursos de Farmácia e Bioquímica e Matemática, incompletos.

Do total de alunos respondentes (16), quatorze 87,5\% deles não estavam trabalhando no momento ou exercendo alguma atividade remunerada. Apenas dois alunos $12,5 \%$ referiram estar trabalhando, sendo que um ministra aulas particulares e outro é monitor bolsista na própria instituição.

Solicitamos aos alunos que citassem se até este momento do curso de graduação, o tema Reabilitação/Deficiências havia sido abordado, discriminando a situação e/ou disciplina. Foi possível constatar, pelas respostas de quatro alunos, situações e/ou disciplinas nas quais o tema havia sido abordado, que foram Introdução á Enfermagem e Psicologia; três desses alunos não especificaram a disciplina. Os demais (12), referiram que o tema não havia sido abordado até então.

Quanto ao conhecimento dos alunos sobre Reabilitação, estes expressaramse de maneira a tentar elaborar um conceito. Considerando a diversidade e riqueza de opiniões, reproduziremos as respostas dos alunos:

"processo que permite a recuperação dos movimentos, sentidos que foram danificados, em um acidente, PCR, etc".

"trabalho elaborado para integrar o indivíduo às suas funções na sociedade".

"processo de recuperação ou a melhora do quadro clínico do paciente".

"processo cujo objetivo é atingir uma melhora no estado de saúde do paciente, para que ele possa se reintegrar à sociedade tendo uma vida norma".

"recuperação do paciente, para ter uma vida normal ou voltar a ter as atividades que tinha antes do acidente ou da doença. Áreas que trabalham com reabilitação: fisioterapia e T.O”.

"estado de recuperação do paciente".

"processo pelo qual tenta-se eliminar a causa de uma determinada doença para que o indivíduo volte a ter saúde".

“devolver ao indivíduo o 'viver' de forma saudável, tanto física quanto psicologicamente".

"Iratamento inserido num processo que exige estudo, observação, exercícios fisicos e psíquicos que leva à cura ou restabelecimento".

"recuperação do estado físico e/ou mental, proporcionando condições de vida sem dependência de terceiros (total ou parcial)". 
" uma série de mecanismos utilizados em pacientes que não podem se movimentar sozinho, são exercícios com acompanhamento intenso até sua melhora".

"método para inserir uma pessoa que tenha sofrido, alguma deficiência e precisa de atenção para voltar a realizar tarefas que fazia antes de se acidentar".

"tratamento de determinada deficiência ou doença incurável, ex: ADDS, deficientes mentais".

"capacitar novamente".

"readquirir uma condição ativa que foi perdida por alguma circunstância". "métodos que propiciam a melhora e recuperação de um paciente traumatizado, marginalizado, etc".

Quanto as expectativas expressas pelos alunos para o ensino de reabilitação no curso de graduação, os conteúdos citados serão apresentados em tópicos a seguir:

- ensino de conceitos básicos de reabilitação e/ ou deficiências, reabilitação física e psicologica;

- desenvolver o cuidar em reabilitação de clientelas específicas como, queimados, seqüelas de paralisia infantil, tetraplégicos, deficientes físicos, vítimas de acidentes, pacientes ortopédicos;

- abordagem dos aspectos psicologicos e sociais da pessoa em reabilitação;

- programa que abranja a área de atuação do enfermeiro em reabilitação;

Ainda, quanto às expectativas dos alunos para o ensino de reabilitação, segundo $14(87,5 \%)$ deles, o conteúdo anteriormente citado deveria ser desenvolvido na forma de uma disciplina específica teórica e prática, sendo que outros 2 alunos $(12,5 \%)$ citaram uma disciplina té́rica optativa. Todos os alunos respondentes consideram necessário o ensino de reabilitação ao longo do curso de graduação em enfermagem, não especificando o semestre ou o momento que isso possa ocorrer.

\section{CONCLUSÃO}

Havia 61 e 79 alunos matriculados, respectivamente no oitavo e segundo semestres do Curso de Graduação em Enfermagem totalizando, então, a entrega de 140 questionários com a devolução de 21 questionários, sendo 5 de alunos do oitavo e 16 de alunos do segundo semestre. 
Conforme os resultados apresentados nos foi possível verificar que os alunos, tanto do segundo semestre quanto do oitavo, consideram importante e necessária a implementação de um ensino formal sobre Reabilitação abordando os aspectos conceituais, físicos e psicossociais, durante o curso de graduação.

É oportuno destacar que quando tentaram elaborar um conceito sobre reabilitação, o "homem" e família foram apontados como o "centro" de um processo de busca, compartilhado com o enfermeiro/ equipe de reabilitação, de um potencial de supostamente este "homem" já trazia consigo. Também, foram lembrados os aspectos sociais via reinserção social do indivíduo, na família e comunidade; aspectos psicológicos, via emoções que circunstaciam o processo de reabilitação ou o significado de reabilitação, para o indivíduo e família.

A esfera do processo de cuidar também foi enfatizada pelos alunos, associada à clientelas mais específicas, bem como o papel do enfermeiro na reabilitação.

Desta maneira compreendemos que o ensino sobre reabilitação no curso de graduação em enfermagem, segundo a opinião de es tudantes de enfermagem deveria explicitar conceitos (reabilitação, deficiência) e a atuação do enfermeiro enfocando o cuidar e outras áreas desenvolvidas por este profissional.

FARO, A.C.M. e The teaching of rehabilitation: expetance of student's nursing.

Rev.Esc.Enf.USP, v.30, n.2, p. 332-9, aug. 1996.

This article shows the nursing student's expetance about rehabilitation teaching during nursing graduation course, $8^{\text {th }}$ semester students and $2^{\text {nd }}$ semester of nursing graduation course answer a specific questionnaire for each grup and they show spectatives characterizing a proposal for the nursing rehabilitation teaching.

UNITERMS: Reahabilitation. Teaching.

\section{REFERÊNCIAS BIBLIOGRÁFICAS}

COMARÚ, M.N. et al subsídios para a determinação das atividades do(a) enfermeiro(a) de reabilitação. Rev. Bras. Enf. DF, v.33, p.173-189, 1980.

NORONHA, R. Experiência participativa mobilizadora de enfermagem - condiçסes prévias para o auto-cuidado. Rev. Bras. Enf. Brasília, v.39, n.1, p.34-43, 1986.

WORLD HEALTH ORGANIZATION. Disability prevention and rehabilitation: a guide for strengthening the basic nursing curriculum. Washington, 1995.

Rev.Esc.Enf.USP, v.30, n.2, p.332-9, ago. 1996. 